\title{
A simple ex vivo pig stomach model for learning endoscopic submucosal dissection
}
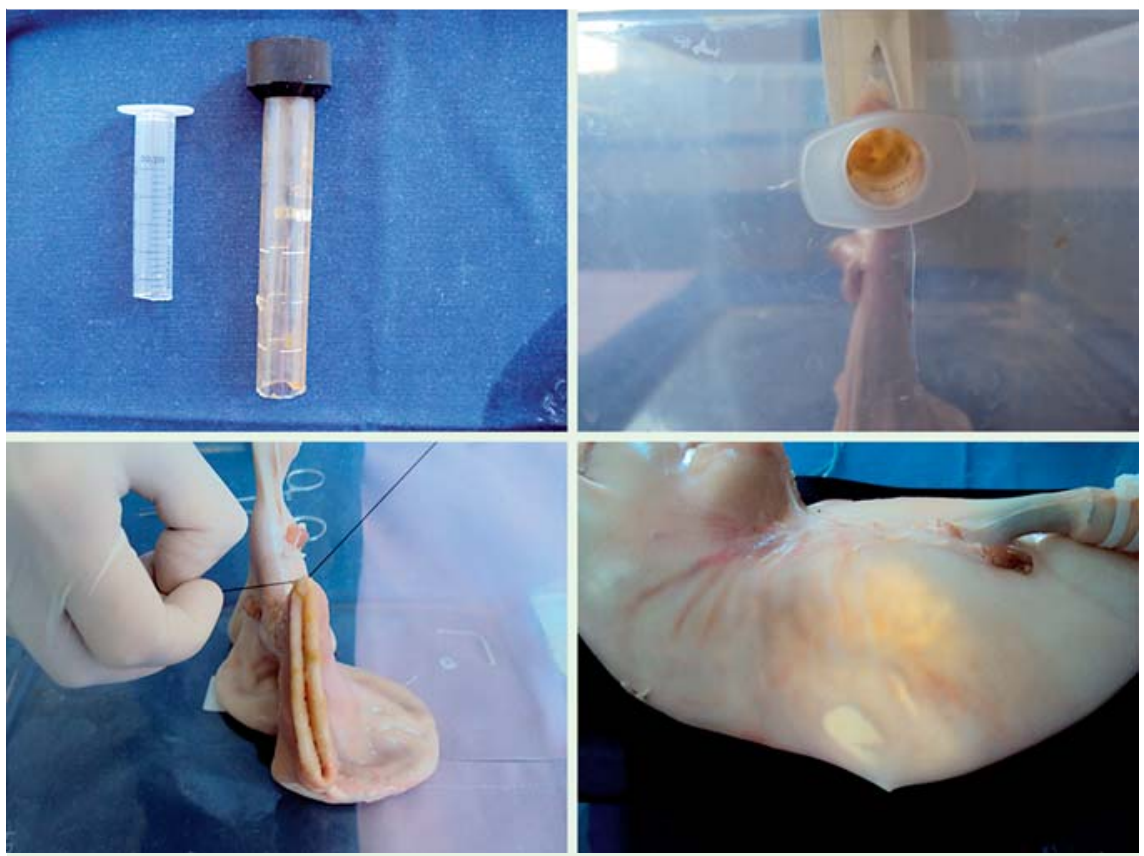

Fig. 1 In vitro pig stomach model placed inside a plastic box and used to perform endoscopic submucosal dissection (ESD) and other advanced endoscopic procedures.

Endoscopic submucosal dissection (ESD) is an accepted technique for the resection of early neoplasia of the luminal gastrointestinal tract. ESD is a routine procedure in many Asian countries [1], however, its utility is now being recognized worldwide [2]. It is an advanced endoscopic technique with a steep learning curve [3]. Training in animal models is thought to improve technical skills and result in a rapid progression in the learning process for various advanced endoscopic procedures including endoscopic retrograde cholangiopancreatography, hemostasis, endoscopic mucosal resection, and ESD [4]. Most models used at the present time are not widely available and are cumbersome to use. Herein we present an ex vivo pig stomach model which we have used to perform ESD and other advanced endoscopic procedures ( $\bullet$ Fig. 1 ). Video 1 shows the key aspects of this model. A hole is made in one of the sides of a plastic box and a syringe is placed in the hole and used to simulate the mouth and esophagus (a "pseudoesophagus"). The pig's stomach placed inside the box is then attached to the syringe using a zip tie and sutures through which the scope and ESD accessories are introduced. Target lesions for resection are produced and the ESD procedure is conducted according to established standards. We recommend that, at an initial stage, the basic movements and techniques of ESD should be learned in ex vivo models, as these are potentially widely available, inexpensive, and mimic human anatomy reliably [5].

\section{Video 1}

A simple plastic box is used to create the model. A hole is made in one of the sides of the box and a syringe is used to simulate the mouth and esophagus. The stomach placed inside the box is then attached to the syringe using a zip tie and sutures. A grounding pad is used to connect the stomach to the electrosurgical unit. Endoscopic submucosal dissection (ESD) is then performed using standard accessories such as argon plasma to mark the margins, injection needles, needle-knife, and IT-knife.
Endoscopy_UCTN_Code_TTT_1AU_2AB

Competing interests: None

\section{Nicolás González ${ }^{1,2}$, Klaus Mönke- müller ${ }^{1}$, C. Mel Wilcox ${ }^{1}$, Andrés Taullard $^{2}$, Miguel Villa-Gómez², Adolfo Parra-Blanco ${ }^{3}$}

${ }^{1}$ Division of Gastroenterology and Hepatology, Basil Hirschowitz Endoscopic Center of Excellence, University of Alabama, Birmingham, United States

${ }^{2}$ Department of Gastroenterology, Hospital de Clínicas, Montevideo, Uruguay

${ }^{3}$ Department of Gastroenterology, Pontificia Universidad Católica de Chile, Santiago, Chile

\section{References}

1 Saito Y, Sakamoto T, Fukunaga S et al. Endoscopic submucosal dissection (ESD) for colorectal tumors. Dig Endosc 2009; 21 (Suppl. 01): 7-12

2 Repici A, Hassan C, Carlino A et al. Endoscopic submucosal dissection in patients with early esophageal squamous cell carcinoma: results from a prospective Western series. Gastrointest Endosc 2010; 71: $715-$ 721

3 Gotoda T, Friedland S, Hamanaka $\mathrm{H}$ et al. A learning curve for advanced endoscopic resection. Gastrointest Endosc 2005; 62: $866-867$

4 Parra-Blanco A, González N, González R et al. Animal models for endoscopic training: do we really need them? Endoscopy 2013; 45: 478-484

5 Parra-Blanco A, González N, Arnau MR. Ex vivo and in vivo models for endoscopic submucosal dissection training. Clin Endosc 2012; 45: 350-357

Bibliography

Dol http://dx.doi.org/

10.1055/s-0034-1377942

Endoscopy 2014; 46: E589

(c) Georg Thieme Verlag KG

Stuttgart · New York

ISSN 0013-726X

\section{Corresponding author}

\section{Klaus Mönkemüller, MD, PhD}

Basil Hirschowitz Endoscopic Center of Excellence Division of Gastroenterology and Hepatology

University of Alabama, Birmingham

Endoscopy Unit

JT 664

619 19th Street S

Birmingham

AL 35249

United States

klaus1@uab.edu 